\title{
A Comparison of Cervical Disc Arthroplasty and Anterior Cervical Discectomy and Fusion in Two-Level Cervical Disc Degenerative Disease
}

\author{
Aron D Rovner* \\ Department of Orthopedic Surgery, Hudson Regional Medical Center, USA
}

*Corresponding author : Aron D Rovner, Department of Orthopedic Surgery, Hudson Regional Medical Center, USA.

\section{Abstract}

Anterior cervical discectomy and fusion (ACDF) has been used to treat degenerative cervical spine diseases for almost six decades. Cervical disc arthroplasty (CDA) has emerged as a promising potential alternative to ACDF in appropriately selected patients. Despite a history of excellent outcomes after ACDF, the question as to whether fusion leads to adjacent segment degeneration remains unanswered. Early clinical outcomes show that CDA is as effective as the standard ACDF. However, it is also associated with a number of complications. Although there is no definitive evidence that cervical disc replacement reduces the incidence of adjacent segment degeneration, it does show other advantages; for example, faster return to work, and reduced need for postoperative bracing.

Keywords: Anterior cervical discectomy and fusion; Cervical disc arthroplasty; Adjacent segment degeneration

\section{Introduction}

Degenerative changes within the intervertebral discs and endplates change the patterns of loading on the vertebral bodies and the associated spinal structures. Cervical degenerative disc disease (DDD) results from the spinal spondylosis and can lead to deterioration of the intervertebral discs of the spine. Desiccation of the discs causes abnormal motion of the spinal column. It can lead to further deterioration due to increased stress on the facet joints, spinal ligaments and tendons, and traversing neurological tissues [1]. The symptoms include pain in the neck, arms, weakness and paresthesia associated with nerve root compression. Disc herniation, osteophytes, and kyphosis can occur which leads to spinal cord compression and myelopathy. Choosing the correct or most optimal treatment is very challenging due to the various comorbidities and psychosocial conditions [1]. A number of modalities have been proposed for the treatment of cervical DDD. It can be managed either non-surgically or surgically. Surgery to treat cervical DDD is generally considered in cases where neurological symptoms are present, such as persistent arm numbness and/or weakness. Surgery may be recommended to alleviate pressure on the nerve. It is also considered when there is severe chronic pain which is not adequately relieved after at least six months of nonsurgical treatments, and daily activities become difficult.

The two most common types of surgery for cervical DDD are

a) Anterior cervical discectomy and fusion (ACDF)

b) Cervical disc arthroplasty (CDA)

\section{Anterior Cervical Discectomy and Fusion (ACDF)}

ACDF is a proven treatment modality for single or multilevel cervical DDD with satisfactory clinical outcomes, since the 1950s, when it was introduced by Robinson and Smith [2]. ACDF is the current gold standard for managing symptomatic anterior cervical DDD [3]. ACDF remains the most commonly performed surgery for symptomatic disc herniations that have failed conservative treatment [4]. ACDF is a surgical procedure to treat nerve root or spinal cord compression by decompressing the spinal cord and nerve roots of the cervical spine with a discectomy, followed by inter vertebral fusion to stabilize the corresponding vertebrae [5]. It involves removing the symptomatic cervical disc and placing bone graft to encourage bony fusion of the upper and lower 
vertebral body. This further encourages cervical fusion to maximize stability and maintain disc space height to decrease the likelihood of foraminal stenosis.

Indications: ACDF is used to treat pain due to inflamed nerve root. This can be caused by [6]

1. A herniated disc when other non-surgical treatments have failed. The nucleus pulposus of the herniated disc bulges out through the annulus and presses on the nerve root next to it.

2. Degenerative disc disease (spondylosis). Small tears may occur in the annulus which leads to inflammation of the nerve root.

3. Cervical radiculopathy or myelopathy.

Technique: The aim of the procedure is to remove a herniated or degenerative disc in the neckand remove pressure from the spinal nerves and to realign and stabilize the spinal segment [6]. It provides excellent visualization for central and bilateral foraminal decompression without manipulation of neural structures. The procedure involves an anterior decompression of the disc space which is followed by interbody grafting and fusion. Bony material (either autograft or allograft) is placed into the intervertebral space in order to stimulate healing and fusion. Supplemental anterior plating is performed to stablilize the fusion site, and in a few cases posterior instrumentation may provide additional fixation.

\section{The procedure includes the following steps:}

(1) The use of an anterior approach to the cervical spine, most commonly the Smith-Robinson approach medial to the sternocleidomastoid muscle and the carotid sheath.

(2) Confirmation of the proper spinal level.

(3) Elevation of the longus colli muscle, which acts as a cuff for the placement of retractors.

(4) Removal of the involved disc and decompression of the spinal cord and nerve roots. This is facilitated by disc space distraction, most commonly via distraction pins. Osteophytes along the floor of the spinal canal impinging on the spinal cord are removed with a burr. Soft disc and annular materials are also removed, usually with curettes and rongeurs. Uncovertebral osteophyte resection and foraminotomies are completed to decompress the exiting nerve roots.

(5) Carpentry and decortication of the end plates in preparation for fusion.

(6) Sizing of the disc space followed by insertion of an interbody graft.

(7) Anterior fixation, most commonly via application of a plate-and-screw construct.

(8) Haemostasis and closure.
There are a number of considerations to evaluate when deciding which type of bone graft options to use. The main factors to be taken into account include:

- $\quad$ Type of spinal fusion (e.g. ALIF, PLIF, posterolateral gutter)

- The number of levels of the spine involved

- Location of fusion - (neck fusion or lumbar fusion)

- Patient risk factors for non-fusion (e.g. if patient is obese, a smoker, poor bone quality)

- $\quad$ Surgeon experience and preference.

Complications: ACDF sacrifices the mobility at the operated disc level which may be an important risk factor for adjacent segment degeneration (ASD). Multilevel fusion could significantly alter the normal biomechanics of the cervical spine by increasing intradiscal pressure and mobility at the adjacent segment [8-12]. There are reports of this therapy causing swelling of soft tissue which in turn can cause life-threatening complications due to difficulty swallowing and pressure on the respiratory tract. With multi-level ACDF, the pseudarthrosis risk is heightened in this setting.

The long-segment ACDF has been reported to cause a number of complications. Swank et al [12] revealed that the incidence of non-union for ACDF varied depending on the number of disc levels involved and is reported to be $44 \%$ in 2-level fusion. Lowery and McDonough [13] reported the incidence of anterior plating failures to be associated with the number of operated levels and was $36 \%$ in 2-level fusion. Geisler et al. [14] reported the reoperation rates after cervical plate stabilization increased as the number of operated levels increased and was $6.5 \%$ in 2-level fusion. Chung et al. [15] concluded that multilevel fusion was an important predictor of the development of ASD and was 32.1\% in multilevel fusion (Table 1).

Table 1: Summary of complication and their incidence rate [16-22].

\begin{tabular}{|c|c|}
\hline Complications & Complication Rate (\%) \\
\hline Wound infection & $0.1-9.5$ \\
\hline Dysphagia & $0.15-9.5$ \\
\hline RLN Palsy & $0.05-7.1$ \\
\hline Post-op hematoma & $0.2-5.6$ \\
\hline Horner's Syndrome & $0.02-3.6$ \\
\hline Durotomy & $0.5-1.3$ \\
\hline
\end{tabular}

Other complications are pharyngeal and oesophageal perforation, worsening neurology, graft extrusion and mortality.

\section{Cervical Disc Arthroplasty (CDA)}

CDA emerged as a new motion-sparing alternative to fusion. Over the past decade, it has become an acceptable surgical treatment for cervical radiculopathy and retrodiscal myelopathy. CDA was developed to preserve subaxial cervical spine biomechanics and natural segmental motion without fusion. The hope was to avoid the complications of non-union and accelerated adjacent segment 
pathology associated with ACDF.m With CDA, instead of placing bone in the intervertebral space, an artificial disc is placed instead. In contrast to ACDF, an anterior plate is not needed to stabilize the adjacent vertebra and an external brace is not needed either. Since it maintains the usual intervertebral disc space, the movement of the spine is preserved. Maintenance of position and motion has been suggested to decrease the risk of adjacent segment degenerative disease that is seen with ACDF [8].

\section{Indications}

Radiculopathy caused by disc herniation (soft or hard)

- $\quad$ Radiculopathy caused by foraminal osteophytes

- Myelopathy due to a soft disc herniation

- $\quad$ Failure of conservative management of single-level disc/ spondylosis meeting the appropriate criteria

\section{Contraindications}

- Isolated axial neck pain

- Ankylosing spondylitis

- Pregnancy

- Rheumatoid arthritis

- Autoimmune disease

- Diffuse idiopathic skeletal hyperostosis Severe spondylosis with bridging osteophytes

- Ossification of the posterior longitudinal ligament

- $\quad$ Severe osteoporosis/osteopenia

- Active malignancy

- $\quad$ Insulin dependent diabetes mellitus

- Human immunodeficiency virus, hepatitis B/C

- $\quad$ Morbid obesity

- Absence of motion less than 2 degrees

- Instability on dynamic radiographs

- $\quad$ Posterior facet arthrosis

\section{Artificial Cervical Disc}

Mobi-C ${ }^{\circledR}$ Cervical Disc Prosthesis (two-level) received premarket approval of August 23, 2013. (P110009). It consists of two metals (cobalt-chrome endplates and a plastic (ultrahigh molecular weight polyethylene) insert that fits between the endplates. The device is placed between two adjacent neck bones (cervical vertebrae) to replace a diseased cervical disc at two adjacent levels that are causing arm pain and/or weakness or numbness. It is intended for skeletally mature patients (people who have stopped growing) to replace two adjacent cervical discs in the neck (from C3-C7) following removal of the discs for conditions that result from diseased or bulging discs at two adjacent spinal levels.
The two devices should help stabilize the operated spinal levels. Unlike a fusion procedure the Mobi-C $₫$ Cervical Disc Prosthesis is designed to allow motion at the operated spinal levels. The effects of removing the diseased discs should include pain relief and improved function.

The use of the Prestige-LP and ZERO-P Spacer implantations is safe and effective. At 5 years after surgery, CDA with PrestigeLP is superior in terms of ROM of the total cervical spine, FSU, and inferior adjacent segment. It also has a relatively low occurrence rate of ASD. This procedure may be a suitable choice for the treatment of contiguous 2-level CDDD [23].

Complications: Adverse events specifically associated with CDA can be categorized by type: implant failure/wear, boneimplant failures, iatrogenic deformity, segmental kyphosis, failed kinematics, neurologic injury, and infection. Another major risk factor that is often unanticipated is the host response to the arthroplasty, resulting in heterotopic ossification (HO) and osteolysis [24].

\section{Comparison of ACDF and CDA}

The primary goals of cervical disc replacement in the treatment of cervical disc herniation or cervical spondylosis are to preserve motion, allow patients to quickly return to routine activities, and prevent later adjacent level degeneration after removing local disc pathology. Artificial cervical disc replacement can eliminate axial neck pain, further indicating that this neck pain is not from the pathology of other parts, such as the posterior facet joints and muscles, but from the pathology of cervical disc itself. The use of an artificial joint instead of fusion to retain mobility at the level of operation has long been proposed. A metal-on-metal, ball-in-socket Cummins-Bristol design reported outcomes in 1998 [25]. Not only does it have the potential to provide a better range of movement, but it also theoretically reduces motion and pressure at adjacent segment and hence incidence of ASD. Nonetheless, a number of complications such as screw pullout had been reported and surgical removal of the hardware proved to be considerably difficult [25].

The literature has however not shown arthroplasty conferring significant long-term advantage. Another systemic review [26] suggested no superiority of cervical total disc replacement relative to fusion operation. Another meta-analysis [27], showed that arthroplasty does not reduce the rate of ASD compared to ACDF. More studies are required to confirm its efficacy and safety.

Cervical Artificial Disc (Two Level) A 2019 Ontario health technology assessment Pron et al. (2019) examined the effectiveness, safety, durability, and cost-effectiveness of C-ADR versus fusion for treating cervical DDD [28]. In two studies of C-ADR for two-level disease, C-ADR was statistically superior to fusion surgery for the same primary outcome. C-ADR was also noninferior to fusion for perioperative outcomes (e.g., operative time, blood loss), patient satisfaction, and health-related quality of life. C-ADR was superior to fusion for recovery and return to work, had higher technical success, and had lower rates of re-operation at the index 
site. It also maintained motion at the index-treated cervical level, but evidence was insufficient to determine if adjacent-level surgery rates differed between C-ADR and fusion. Current evidence was insufficient to determine the long-term durability of C-ADR. The authors concluded that for carefully selected patients with cervical degenerative disc disease, C-ADR provides patient-important and statistically significant reductions in pain and disability. Unlike fusion, C-ADR allows people to maintain relatively normal cervical spine motion.

A study was performed by Gao et al. (2019) to present a longterm clinical and radiographic comparison between the Prestige LP cervical disc replacement and the Zero-P spacer cervical disc fusion in the treatment of patients with symptomatic 2-level cervical degenerative disease. The authors concluded that the use of the Prestige-LP and ZERO-P Spacer implantations is safe and effective. At 5 years after surgery, CDA with Prestige-LP is superior in terms of ROM of the total cervical spine, FSU, and inferior adjacent segment. It also has a relatively low occurrence rate of ASD [29].

Zhao et al. (2018) conducted a systematic review and metaanalysis to compare the efficacy and safety of ACDR and ACDF in patients with 2 contiguous levels cervical spondylosis. The authors concluded that for bi-level cervical spondylosis, ACDR appears to provide superior clinical effectiveness and safety effects than ACDF [30].

A systematic review was conducted by Joaquim et al. (2017) of clinical studies evaluating patients who underwent multilevel cervical disc arthroplasty (CDA) (2 or more levels). The authors reported that multilevel CDA was at least as safe and effective as ACDF, with preservation of cervical motion when compared with ACDF and with fewer reoperations [31]. Multilevel CDAs are clinically effective as single-level surgeries, with good clinical and radiological outcomes. Some studies reported a higher incidence of heterotopic ossification in multilevel CDA when compared with single-level procedures, but without clinical relevance during the follow-up period. The authors concluded that the current literature supports the use of multilevel CDA but caution is necessary regarding the more restrictive indications for CDA when compared with ACDF.

Gornet et al. (2017) conducted a prospective, multicenter randomized control trial to compare the efficacy and safety of arthroplasty using the Prestige LP cervical disc with those of ACDF for the treatment of DDD at 2 adjacent levels. The authors concluded that arthroplasty with the Prestige LP cervical disc is as effective and safe as ACDF for the treatment of cervical DDD at 2 contiguous levels and is an alternative treatment for intractable radiculopathy or myelopathy at 2 adjacent levels [32].

Lanman et al. (2017) assessed the long-term clinical safety and effectiveness in patients undergoing anterior cervical surgery using the Prestige LP ADR prosthesis to treat degenerative cervical spine disease at 2 adjacent levels compared with ACDF. The authors concluded that the Prestige LP ADR demonstrated statistical superiority over fusion for overall success and implanted at 2 adjacent levels, maintains improved clinical outcomes and segmental motion and is a safe and effective alternative to fusion [33].

A 2017 Hayes Medical Technology Comparative Effectiveness Review [34] included eight studies that examined the effectiveness and safety of 2-level artificial cervical TDR compared with ACDF. The review found that two-level TDR is at least as effective as ACDF and sometimes more effective for improving symptoms of patients with cervical DDD, with clinically meaningful effects lasting as long as 7 years. The purpose of a study by Radcliff et al. (2016) was to report the outcome of a study of 2-level cervical TDR (Mobi-C $₫$ ) versus ACDF. The authors concluded that there was significantly greater improvement in disease-specific outcome measures and a lower rate of reoperation in the 2-level disc replacement patients versus ACDF control patients [35].

Zou et al. (2016) conducted a meta-analysis of randomized controlled trials to evaluate the clinical effects requiring surgical intervention between ACDF and CDA at two contiguous levels cervical disc degeneration. The authors concluded that CDA group is equivalent and, in some aspects, has more significant clinical outcomes than the ACDF group at two contiguous levels cervical disc degeneration [36].

\section{Conclusion}

There is no clear evidence of superiority of CDA vs ACDF. Over the past 10 years, CDA has emerged as an alternative to ACDF for carefully selected patients. To date, definitive evidence to support a reduction in the incidence of adjacent segment disease following index level CDA surgery is still lacking. The main advantages of CDA are more rapid return to work, the avoidance of harvesting iliac crest bone graft (using instead) allograft bone, and the lack of necessity for postoperative bracing. It is not a new gold standard for treating cervical spondylotic radiculopathy or myelopathy because of the multiplicity of contraindications and complications which may require life-long surveillance. Both surgical procedures are advantageous in cases of cervical degenerative diseases, which could not be treated non-surgically.

\section{Acknowledgement}

None.

\section{Conflict of Interest}

No conflict of interest.

\section{References}

1. Buser Z, Ortega B, D Oro A, Pannell W, Cohen JR, et al. (2018) Spine Degenerative Conditions and Their Treatments: National Trends in the United States of America. Global spine J 8(1): 57-67.

2. Smith GW, Robinson RA (1958) The treatment of certain cervical-spine disorders by anterior removal of the intervertebral disc and interbody fusion. J Bone Joint Surg Am 40-A(3): 607-624.

3. Agrillo U, Faccioli F, Fachinetti P, Gambardella G, Guizzardi G, et al. (1999) Guidelines for the diagnosis and management of the degenerative diseases of the cervical spine. J Neurosurg Sci 43(1): 11-14. 
4. Bible J, Kang J (2016) Anterior cervical discectomy and fusion. Surgical indications and outcome 28(2): 80-83.

5. Shayan Abdollah Zadegan, Seyed Behnam Jazayeri, Aidin Abedi, Hirbod Nasiri Bonaki, Alexander Vaccaro, et al. (2018) Corticosteroid Administration to Prevent Complications of Anterior Cervical Spine Fusion: A Systematic Review. Global Spine J 8(3): 286-302.

6. Rhee J, Ju K (2016) Anterior cervical discectomy and fusion. JBJS Essent Surg Tech 6(4): e37.

7. Rhee J, Ju KL (2016) Anterior Cervical Discectomy and Fusion. JBJS Essent Surg Tech 6(4): e37.

8. Cherubino P, Benazzo F, Borromeo U, Perle S (1990) Degenerative arthritis of the adjacent spinal joints following anterior cervical spinal fusion: clinicoradiologic and statistical correlations. Ital J Orthop Traumatol 16(4): 533-543.

9. Baba H, Furusawa N, Imura S, Kawahara N, Tsuchiya H, et al. (1993) Late radiographic findings after anterior cervical fusion for spondylotic myeloradiculopathy. Spine (Phila Pa 1976) 18(15): 2167-2173.

10. Goffin J, van Loon J, Van Calenbergh F, Plets C (1995) Long-term results after anterior cervical fusion and osteosynthetic stabilization for fractures and/or dislocations of the cervical spine. J Spinal Disord 8(6): 500-508.

11. Hilibrand AS, Carlson GD, Palumbo MA, Jones PK, Bohlman HH (1999) Radiculopathy and myelopathy at segments adjacent to the site of a previous anterior cervical arthrodesis. J Bone Joint Surg Am 81(4): 519-528.

12. Ji-Sheng Shi, Bin Lin, Chao Xue, Hai Shen Zhang, Zhi Da Chen, et al. (2015) Clinical and radiological outcomes following hybrid surgery in the treatment of multi-level cervical spondylosis: over a 2-year followup. J Orthop Surg Res 10: 185.

13. Swank ML, Lowery GL, Bhat AL, McDonough RF (1997) Anterior cervical allograft arthrodesis and instrumentation: multilevel interbody grafting or strut graft reconstruction. Eur Spine J 6(2): 138-143.

14. Lowery GL, McDonough RF (1998) The significance of hardware failure in anterior cervical plate fixation. Patients with 2- to 7-year follow-up. Spine (Phila Pa 1976) 23(2): 186-187.

15. Geisler FH, Caspar W, Pitzen T, Johnson TA, et al. (1998) Reoperation in patients after anterior cervical plate stabilization in degenerative disease. Spine (Phila Pa 1976) 23(8): 911-920.

16. Chung JY, Kim SK, Jung ST, Lee KB (2014) Clinical adjacent-segment pathology after anterior cervical discectomy and fusion: results after a minimum of 10-year follow-up. Spine J 14(10): 2290-2298.

17. Moatz B, Tortolani JP (2012) Cervical Disc Arthroplasty: Pros and cons. Surg Neurol Int 3(3):S216-S224.

18. Flynn TB (1982) Neurologic complications of anterior cervical interbody fusion. Spine (Phila Pa 1976) 7(6): 536-539.

19. Fountas KN, Kapsalaki EZ, Nikolakakos LG, Smisson HF, Johnston KW, et al. (2007) Anterior cervical discectomy and fusion associated complications. Spine (Phila Pa 1976) 32(21): 2310-2317.

20. Gruskay JA, Fu M, Basques BA, Bohl DD, Buerba RA, et al. (2016) Factors Affecting Length of Stay and Complications After Elective Anterior Cervical Discectomy and Fusion: A Study of 2164 Patients From The American College of Surgeons National Surgical Quality Improvement Project Database (ACS NSQIP). Clin Spine Surg 29(1): E34-42.
21. Nanda A, Sharma M, Sonig A, Ambekar S, Bollam P (2014) Surgical complications of anterior cervical diskectomy and fusion for cervical degenerative disk disease: a single surgeon's experience of 1,576 patients. World Neurosurg 82(6):1380-1387.

22. Riley LH, Robinson RA, Johnson KA, Walker AE (1969) The results of anterior interbody fusion of the cervical spine. Review of ninety-three consecutive cases. J Neurosurg 30(2): 127-133.

23. Tew JM, Mayfield FH (1976) Complications of surgery of the anterior cervical spine. Clin Neurosurg 23:424-434.

24. Gao X, Yang Y, Liu H, Meng Y, Zeng J, et al. (2019) A Comparison of Cervical Disc Arthroplasty and Anterior Cervical Discectomy and Fusion in Patients with Two-Level Cervical Degenerative Disc Disease: 5-Year Follow-Up Results. World Neurosurg 122: e1083-e1089.

25. Moatz B, Tortolani PJ (2012) Cervical disc arthroplasty: Pros and cons. Surg Neurol Int 3(3): S216-224.

26. Cummins BH, Robertson JT, Gill SS (1998) Surgical experience with an implanted artificial cervical joint. J Neurosurg 88(6):943-948.

27. Health Quality Ontario (2019) Cervical artificial disc replacement versus fusion for cervical degenerative disc disease: a health technology assessment. Ont Health Technol Assess Ser 19(3):1-223.

28. Gao X, Yang Y, Liu H, Meng Y, Zeng J, et al. (2019) A comparison of cervical disc arthroplasty and anterior cervical discectomy and fusion in patients with two-level cervical degenerative disc disease: 5-year follow-up results. World Neurosurg 122: e1083-e1089.

29. Yang W, Si M, Hou Y, Nie L (2018) Superiority of 2-level total disk replacement using a cervical disk prosthesis versus anterior cervical diskectomy and fusion. Orthopedic 41(6):344-350.

30. Zhao H, Duan LJ, Gao YS, Yang YD, Tang XS, et al. (2018) What is the superior surgical strategy for bi-level cervical spondylosis-anterior cervical disc replacement or anterior cervical decompression and fusion?: a meta-analysis from 11 studies. Medicine (Baltimore) 97(13): e0005.

31. Gornet MF, Lanman TH, Burkus JK, Hodges SD, McConnell JR, et al. (2017) Cervical disc arthroplasty with the Prestige LP disc versus anterior cervical discectomy and fusion, at 2 levels: Results of a prospective, multicenter randomized controlled clinical trial at 24 months. J Neurosurg Spine 26(6): 653-667.

32. Burkus JK, Haid RW, Traynelis VC, Mummaneni PV (2017) Long-term clinical and radiographic outcomes of the Prestige LP artificial cervical disc replacement at 2 levels: results from a prospective randomized controlled clinical trial. J Neurosurg Spine 27(1): 7-19.

33. Hayes (2015) Inc. Medical Technology Directory. Lumbar total disc replacement for degenerative disc disease. Lansdale,PA.

34. Radcliff K, Coric D, Albert T (2016) Five-year clinical results of cervical total disc replacement compared with anterior discectomy and fusion for treatment of 2-level symptomatic degenerative disc disease: a prospective, randomized, controlled, multicenter investigational device exemption clinical trial. J Neurosurg Spine 25(2): 213-224.

35. Zou S, Gao J, Xu B, Lu X, Han Y, et al. (2016) Anterior cervical discectomy and fusion (ACDF) versus cervical disc arthroplasty (CDA) for two contiguous levels cervical disc degenerative disease: a meta-analysis of randomized controlled trials. Eur Spine J 26(4): 985-997. 